\title{
Maggots in the ear - a case series
}

\author{
Srinivasa V. ${ }^{1}$, Arivazhagan G.B. ${ }^{2}$, Balu K.G. ${ }^{3}$, Kayarkar D. ${ }^{4}$ \\ ${ }^{1}$ Dr. Srinivasa V., Professor and HOD, ${ }^{2}$ Dr. Ganesh Bala Arivazhagan, Associate Professor, ${ }^{3}$ Dr. Balu K.G., \\ Postgraduate, ${ }^{4}$ Dr. Darshan Kayarkar, Postgraduate, all authors are affiliated with Department of Otorhinolaryngology, \\ Vinayaka Mission's Medical College, Vinayaka Mission Research Foundation-DU, Keezhakasakudi, Karaikal, \\ Pondicherry, India.
}

Corresponding Author: Dr. Ganesh Bala Arivazhagan, Associate Professor, Department of Otorhinolaryngology, Vinayaka Mission's Medical College, Vinayaka Mission Research Foundation-DU, Keezhakasakudi, Karaikal, Pondicherry, India. Email: balukg1947@gmail.com

\begin{abstract}
Myiasis of the ear is an infestation of the ear by maggots (the larval stage of flies). In literature there are only few cases reported about aural myiasis. It is more common to occur in tropical regions, were humidity and warm weather provide a good environment for this infestation. In this paper, we report 9 cases of unilateral ear ache and ear discharge presented to our department. Otoscopic examination showed 5-15 live larvae in all of them with blood stained serosanguineous discharge. The removed larvae were identified by microbiologist to belong to the Sarcophagidae family.
\end{abstract}

Key words: Maggots, Ear, Sarcophagidae, Lifecycle

\section{Introduction}

Aural myiasis or automyiasis is the infestation of external ear and/or middle ear with dipterous larvae. The myiasis, derived from the ancient Greek word 'myia' which means fly, is an infestation of the tissues and organs caused by fly (diptera) larvea [1]. It is a common infestation among mammals. In humans, it is seen more in rural areas where people are in more direct contact with animals [2]. Although life cycle of a fly depends on species and types of exposure, usually infestation onsets with flies leaving their ova on intact skin, wound or necrotic tissue. The disease occurs when the female fly lays eggs, which shortly will cause clinical manifestations that are related to the body site involved [3]. Larvae hatching from the ova pass into adjacent tissues, and complete their life cycles, and

\section{Case Presentation}

A series of 9 cases presented to our ENT department with complaints of unilateral ear ache and ear discharge with an average time period of 2 weeks duration. Out of the nine patients 6 were female and 2 were male. All the patients were within the age group of 40 to 80 years of age.

Three of them had left sided ear complaints and rest had right sided ear complaints. Of the nine patients a total of seven patients complaints of aural fullness, hard of hearing and foreign body sensation. Five of them had complaints of blood stained discharge and 2 of them had tinnitus episodes. None of them had associated giddiness or vertigo episodes.

Manuscript received: $4^{\text {th }}$ February 2019

Reviewed: $14^{\text {th }}$ February 2019

Author Corrected: $20^{\text {th }}$ February 2019

Accepted for Publication: $26^{\text {th }}$ February 2019 transform into adult forms. Myiasis can encounter us in various forms in clinical practice. In the field of otolaryngology, it may affect the ears, nose and paranasal sinuses, nasopharynx, oral cavity, and skin of the head and neck region. They are classified as ecologically obligatory, facultative or accidentally localized parasites. Anatomically they are classified according to the location of the larvae in the host [4].

Risk factors for myiasis in humans are chronic suppurative otitis media, low socioeconomic status, swimming in stagnant water, and diabetes mellitus [5]. Other possible predisposing factors include neglected children, old age, mental retardation, and poor personal hygiene. 
All the nine patients underwent otological examination among which pre auricular area showed tenderness in 4 patients. Pinna and post auricular area were normal in all the patients. External auditory canal examination of all patient showed live larvae in the canal with blood stained serosanguigjneous discharge. Granulation tissue was present in the external auditory canal in seven patients. Tympanic membrane was not visualized.

Table No-1: Age distribution:

\begin{tabular}{|c|c|c|}
\hline Serial No & Age group (years) & No of patients \\
\hline 1 & $40-50$ & 3 \\
\hline 2 & $50-60$ & 3 \\
\hline 3 & $60-70$ & 2 \\
\hline 4 & $70-80$ & 1 \\
\hline
\end{tabular}

Table No-2: Presenting Complaint.

\begin{tabular}{|c|c|c|}
\hline Serial No & Complaints & No of patients \\
\hline 1 & Ear Ache & 9 \\
\hline 2 & Ear Discharge & 5 \\
\hline 3 & Blood Stained Discharge & 2 \\
\hline 4 & Tinnitus & 7 \\
\hline 5 & Hard Of Hearing & 7 \\
\hline 6 & Aural Fullness & 7 \\
\hline 7 & Foreign Body Sensation & Nil \\
\hline 8 & Vertigo & 5 \\
\hline
\end{tabular}

Neurological test including finger nose test, Rombergs test, and modified rombergs test were all negative in all the patients. None of them showed any dysdiadochokinesia or elicited spontaneous nystagmus.

Otoendoscopy was done for all the nine patients which showed 5-15 live larvae in all of them with blood stained serosanguineous discharge. Canal wall mucosa was odematous. Out of nine patients seven of them had a perforated tympanic membrane with irregular margin. In all the case middle ear mucosa was inflamed

HRCT temporal bone of the diseased ear was taken for all the patients out of which 2 patients showed evidence of external auditory canal wall erosion with normal intracranial space, with no suspicion of any residual disease

After routine investigations under local anesthesia, removal of larvae fromexternal auditory canal was done with crocodile forceps under microscopic guidance,Hydrogen peroxide wash given. After removal of larvae antiseptic dressing was applied to all the patients.

Larvae were identified by microbiologist to belong to the Sarcophagidae family. Microscopic examination showed segmented larvae measuring approximately 8-14 mm covered with bands of irregularly, and retrogradely arrayed spinous processes. With these characteristics, these larvae were determined to be consistent with wohlfahrtia magnifica species.

All the 9 patients were admitted under ENT ward following the procedure and were given IV antibiotics and daily antiseptic ear dressing for 5 days. Patient improved symptomatically during the course of time. Otoendoscopy was done on the 5 th day which showed a dry ear with canal wall oedema subsided and 7 of them had large central perforation.

Patients were discharged on the 5th day with antibiotic ear drops andadvised to keep ear dry with follow up visitscheduled after one week. On the follow up visit all the patients were symptomatically better with none of them having any ear discharge and ear pain. Otondoscopy were done for all the patients showed a healthy canal wall mucosa with no discharge. Tympanic membrane was intact in 2 of the patients with 7 of them showed a large central perforation $\mathrm{f}$ or which tympanoplasty was planned. 


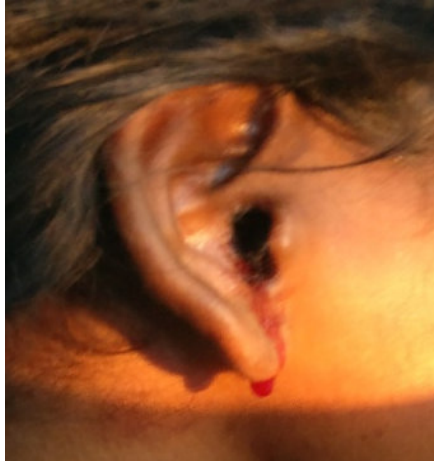

Fig-1

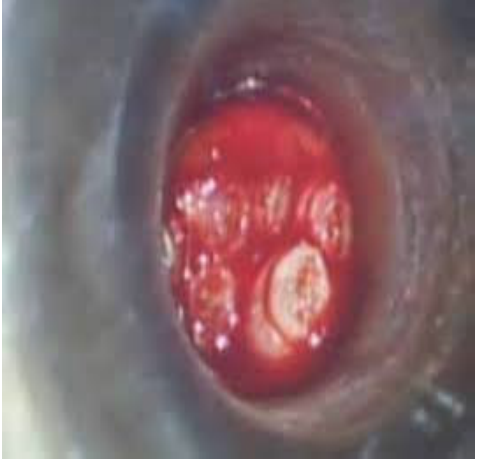

Fig-2

\section{Case Series}

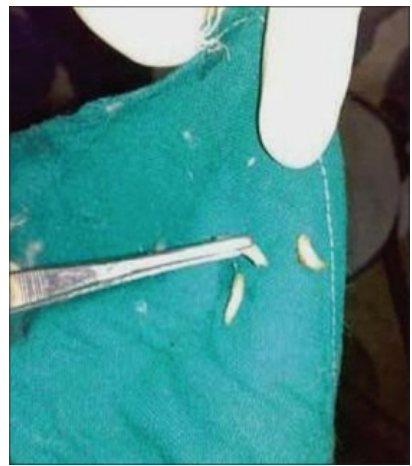

Fig-3

Fig-A: Blood stained ear discharge from the external auditory canal

Fig-B: Ear speculum examination showing blood stained ear discharge with larvae.

Fig-C: larvae removed using crocodile forceps (wohlfahrtiamagnifica)

\section{Discussion}

Myiasis is defined as the Infestation of Dipterous larvae which feeds on host's dead or living tissue, liquid body substances, or ingested food. Myiasis can be seen in various regions, skin, body cavities, and organs. Aural myiasis can manifest itself in various forms including ophthalmomyiasis, nasal myiasis, urogtenital myiasis, intestinal myiasis, and cutaneous myiasis [6]. Myiasis can be classified into either obligatory or facultative infestation. In the former, the host, most commonly the goat and sheep, is an obligatory part of the life cycle of the maggots, while in the latter it is not [7].

The infestation found in this patient (Sarcophagidae family, Wohlfahrtiamagnifica species) is an obligate parasite. The female fly is attracted to normal and pathological secretions of the orifices of mammals [8]. Otomyiasis is quiet rarely seen in healthy people [9]. Literature reviews have detected its presence generally in children, people with poor hygiene or those having predisposing factors. Patients usually present to the hospital complaining of ear pain, hearing loss, purulent or bloody ear discharge, itching in the ear or tinnitus [10,11]. Other possible presentations may include vertigo, facial weakness, neurological manifestations secondary to intracranial involvement.

The symptoms start after the deposited larvae start to feed on the surrounding tissues. The infestation is usually diagnosed by history and clinical examination, which will show the larvae in the ear. It is less likely to need further investigations to diagnose it, because the larvae are usually present near the external auditory canal because they need air for breathing. Complaints of otomyiasis can manifest differently based on the patient's mental health state.

These patients can present with complaints of sensation of foreign substance in the ear, aural itching, pain, bleeding, tinnitus, hearing loss, and vertigo $[12,13]$. In our cases all of them presented with unilateral ear ache and serosanguineous ear discharge. Most of them had blood stained ear discharge, however non of them had any vestibular symptoms.
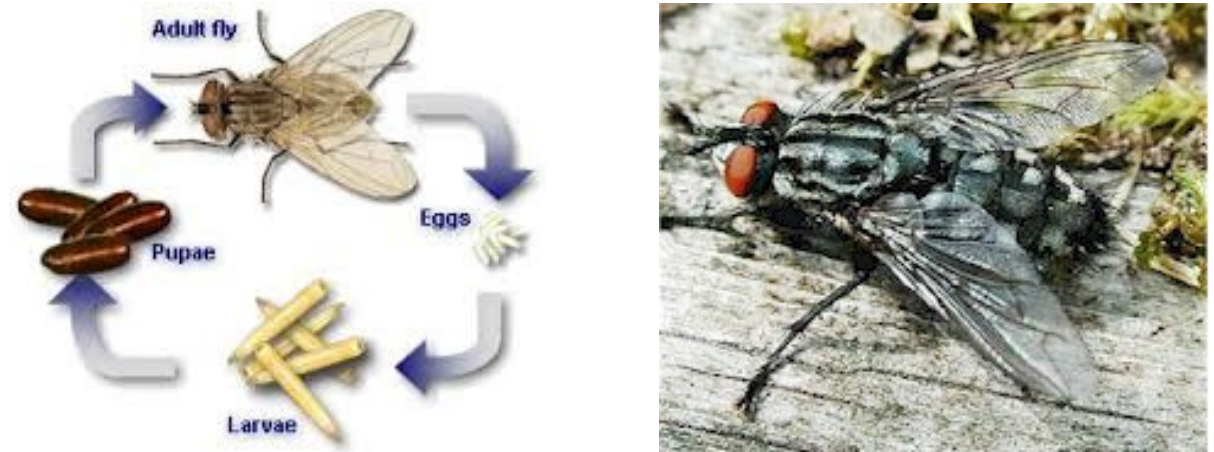

Life Cycle Wohlfahrtia Magnifica 
The treatment of aural myiasis in most cases is nothing more than removal of larvae. It should be followed by irrigation of the external auditory canal with one of the following solutions. Alcohol, chloroform, normal saline, oil, ivermectin, or iodine $[10,11]$. Also, prophylactic broad spectrum antibiotics are usually prescribed to prevent secondary infections. The goal of the irrigation is usually to kill and expel any residual larvae, mainly the ones not visible or accessible on examination.

In literature reviews, the most frequently encountered species of parasites in cases with aural myiasis are cochliomyiahominivorax, wohlfahrtia magnifica, chrysomya bezziana, chrysomya megacephala, and parasarcopha gacrassipalpis [4]. In the cases which reported to our OPD, microscopic examination showed segmented larvae measuring approximately 8$14 \mathrm{~mm}$ covered with bands of irregularly, and retrogradely arrayed spinous processes. With these characteristics, these larvae were determined to be consistent with wohlfahrtia magnifica species.

Otomyiasis is generally a self-limiting disease. Larvae usually leave the host when they become adult larvae. However, during this period because of both mechanical effects of larvae, and collagenases they induce many complications in the patient. These complications can include perforation of the tympanic membrane, destruction of the middle ear, and mastoid cavity, and fatal central nervous system invasion [14]. Mortality rates of otomyiasis combined with nasal myiasis climb to 8 percent [4].

Surgical exploration is sometimes needed in patients when there is suspicion about the extent of the disease or for residual disease. In the case reported here, there was no suspicion of any residual disease and there were no manifestations that may raise the suspension of intracranial extension. Also, CT scan showed intact bony landmarks and normal intracranial space, with no suspicion of any residual disease.If a patient is going to have surgical exploration, CT scan should be done.

Intracranial involvement of patients with aural myiasis must be looked after carefully in all patients, especially in the presence of manifestations that may raise suspicion, for example, clear otorrhea, headache, or seizure. Rectum involvement has been observed rarely [15].

\section{Conclusion}

In conclusion, aural myiasis is a rare infestation of the ear. It occurs usually in patients with risk factors like chronic suppurative otitis media, low socioeconomic status, neglected children, old age, mental retardation, and poor personal hygiene.

In such a scenario Otomyiasis should be kept in mind. A simple autoscopic examination may be a life-saving procedure.

\section{Funding: Nil, Conflict of interest: Nil \\ Permission from IRB: Yes}

\section{References}

1. Hope FW. On insects and their larvae occasionally found in the human body. Trans. R. Entomol. Soc. Lond. 1840:256-71.

2. A. K. Ahmad, E. H. Abdel-Hafeez, M. Makhloof, and E. M, Abdel-Raheem. Gastrointestinal myiasis by Larvae of Sarcophaga sp. and Oestrus sp. in Egypt: report of cases, and endoscopical and morphological studies. The Korean Journal of Parasitology, vol. 49, no. 1, pp. 51-57, 2011.
3. I. Khan, A. Y. Muhammad, and M. Javed, "Risk factors leading to aural myiasis," Journal of Postgraduate Medical Institute, vol. 20, no. 4, 2011.

4. Francesconi F, Lupi O. Myiasis. Clin Microbiol Rev. 2012 Jan; 25 (1):79-105. doi: 10.1128/ CMR. 00010-11.

5. R. P. Lane and R. W. Crosskey, Medical Insects and Arachnids, Chapman \& Hall, London, UK, 1993.

6. Arora S, Sharma JK, Pippal SK, Sethi Y, Yadav A. Clinical etiology of myiasis in ENT: a reterograde period--interval study. Braz J Otorhinolaryngol. 2009; 75: 356-61.

7. F. Francesconia and O. Lupi. Myiasis. Clinical Microbiology, Reviews, vol. 25, no. 1, pp. 79-105, 2012.

8. Osorio J, Moncada L, Molano A, et al. Role of ivermectin in the treatment of severe orbital myiasis due to Cochliomyiahominivorax. Clin Infect Dis. 2006 Sep 15; 43 (6): e57-9. Epub 2006 Aug 8. 


\section{Case Series}

9. Hatten K, Gulleth Y, Meyer T, et al. Myiasis of the external and middle ear. Ann OtolRhinolLaryngol. 2010 Jul; 119(7):436-8.

10. Cho JH, Kim HB, Cho CS, et al. An aural myiasis case in a 54-year-old male farmer in Korea. Korean $\mathrm{J}$ Parasitol. 1999 Mar;37(1):51-3.

11. Magliulo G, Gagliardi M, D'Amico R. Human aural myiasis. Otolaryngol Head Neck Surg. 2000 May;122 (5): 777.

12. Güler S, Sağıt M, Sarı K, Somdaş MA. An Aural Myiasis on the Grounds of Chronic Otitis Media: Case Report. KBB ve BBC Dergisi. 2011;19:172-5.
13. Karaman E, Samasti M, Saritzali G, et al. Otomyiasis by Wohlfahrtia magnifica. Craniofac Surg. 2009 Nov; 20 (6): 2123-4. doi: 10.1097/SCS. 0b013e 3181 bec66e.

14. Werminghaus P, Hoffmann TK, Mehlhorn H, et al. Aural myiasis in a patient with Alzheimer's disease. Eur Arch Otorhinolaryngol. 2008 Jul; 265(7): 851-3. Epub 2007 Nov 21. DOI: 10.1007/s00405-007-0535-2

15. Karabiber H, Oguzkurt DG, Dogan DG, et al. An unusual cause of rectal bleeding: intestinal myiasis. J Pediatr Gastroenterol Nutr. 2010 Oct; 51 (4):530-1. doi: 10.1097/MPG.0b013e3181eb313c.

\section{How to cite this article?}

Srinivasa V, Arivazhagan G.B, Balu K.G, Kayarkar D. Maggots in the ear - a case series. Trop J Ophthalmol Otolaryngol.2019;4(1):30-34.doi:10.17511/jooo.2019.i01.06 